\title{
Dynamic Deformation Monitoring of Lotsane Bridge Using Global Positioning Systems (GPS) and Linear Variable Differential Transducers (LVDT)
}

\author{
Selassie David Mayunga*, M. Bakaone \\ Department of Civil and Environmental Engineering, Botswana University of Science and Technology, \\ Palapye, Botswana \\ Email: *mayungas@biust.ac.bw
}

How to cite this paper: Mayunga, S.D. and Bakaone, M. (2021) Dynamic Deformation Monitoring of Lotsane Bridge Using Global Positioning Systems (GPS) and Linear Variable Differential Transducers (LVDT). Journal of Data Analysis and Information Processing, 9, 30-50.

https://doi.org/10.4236/jdaip.2021.91003

Received: August 12, 2020

Accepted: February 23, 2021

Published: February 26, 2021

Copyright $\odot 2021$ by author(s) and Scientific Research Publishing Inc. This work is licensed under the Creative Commons Attribution International License (CC BY 4.0).

http://creativecommons.org/licenses/by/4.0/

(c) (i) Open Access

\begin{abstract}
The measurements and analysis of deformation of engineering structures such as dams, bridges and high-rise buildings are important tasks for civil engineers. It is evident that, all civil engineering structures are susceptible for deterioration over a period of time. Bridges in particular, deteriorate due to loading conditions, environmental changes, earth movement, material used during construction, age and corrosion of steel. Continuous monitoring of such structure is the most important aspect as it provides quantitative information, assesses the state of the structure, detects unsafe positions and proposes early safety measures to be taken before it can threaten the safety of vehicles, goods and human life. Despite government's efforts to construct roads and highways, bridge deformation monitoring has not been given priority in most of African countries and ultimately causes some bridges to collapse unexpectedly. The purpose of this research is to integrate Global Positioning System (GPS) and Linear Variable Differential Transducers (LVDT) to monitor deformation of a bridge. The horizontal positions of reference and monitoring points were determined using Global Positioning System (GPS) while the vertical deflections, accelerations and strain were determined using Linear Variable Differential Transducers (LVDT). The maximum displacements obtained between zero and first epochs in $\mathrm{x}, \mathrm{y}$ and $\mathrm{z}$ components were $0.798 \mathrm{~m}$, at point LT08, $0.865 \mathrm{~m}$ at point BR13, and $0.56 \mathrm{~m}$ at point LT02 respectively. The maximum deflections for LVDT 1, 2 and 3 are $28.563 \mathrm{~mm}, 31.883 \mathrm{~mm}$ and $40.926 \mathrm{~mm}$ respectively. Finally, the correlation coefficient for the observations was 0.679 with standard deviations of 0.0168 and 0.0254 in $\mathrm{x}$ and $\mathrm{y}$ respectively. Our results identified some slight displacements in horizontal
\end{abstract}


components at the bridge.

\section{Keywords}

Bridge Deformation Monitoring, GPS and Linear Variable Differential Transducers

\section{Introduction}

Structural Health Monitoring (SHM) is a recent concept in civil engineering which aimed at assessing the behavior and safety of all civil engineering structures. The behavior and safety assessment include measurements and analysis of point positions on and away from the structure over different periods to determine the state of the structure. It is evident that all civil engineering structures such as bridges, high-rise buildings, dams, etc. are essential to social, human and economic development of any country. Bridges in particular, are key infrastructures to settlements, towns and cities which are susceptible for deterioration although are built to have life spans above three decades [1]. According to [2] deterioration is termed as a failure of a structure caused mainly by environmental and non-environmental factors such as erosion, earthquake, floods, loading conditions and construction materials which may have been overlooked during the design and construction periods. It is imperative to understand that, a bridge after being constructed it has to undergo static load test to verify the load deformation response. Therefore, continuous monitoring of bridges is an important aspect in obtaining information which helps to detect abnormal behavior of the structures at early stages and propose necessary safety measures before it can threaten the safety of vehicles, goods and human life. [3] pointed out that, continuous monitoring bridges are considered to be a valuable tool to complement other non-destructive methods in improving reliability and extending lifetime of the structure.

Bridge deformation monitoring is grouped into two major parts namely long term and short term [4]. Long term deformation monitoring is caused by a bridge foundation settlement, deck creep and stress relaxation, while short term deformation is caused by the dynamic effects such as wind, temperature, traffic, age and earthquake. Based on the measurements and analysis of data obtained, proper repair or rehabilitation can be conducted to keep the bridge safe and increase the life spans much longer. It is important to mention here that, the cost for monitoring and repair is much lower as compared to reconstruction cost of a new bridge. In recent years we have witnessed bridges collapsing in many parts in the world. In Italy for example, a bridge at Genoa collapsed killing dozens of people and damaged vehicles and other properties (https://www.euronews.com/tag/italya-daki-kopru-kazas-). In South Africa, a pedestrian bridge which was under construction collapsed along M1 highway 
and damaged vehicles and properties. In the Southern District Council of Botswana, a bridge collapsed due to failed culvert which gave-in water pressure at a site of construction. According to a statement issued by the department of Roads, the bridge collapsed due to culvert failure causing loss of properties and resources of construction of a new bridge. Indeed, lack of short and long term bridge monitoring mechanism in most developing countries is a major factor for this phenomenon. Therefore, monitoring of bridges is very vital for safety of good, vehicles and the economic growth of any country. In order to effectively monitor the abnormal behavior of a bridge, a precise monitoring scheme is required. The standard practice for the monitoring of bridges in most developing countries has been periodical visual inspections, relying on inspectors to identify areas and signs of damages or unusual behaviors. Visual inspection is subjective in nature and does not provide reliable results [5] [6]. For decades, roads department at the Ministry of Works and Transport in Botswana has been collecting data on roads and bridge conditions. Data collected includes visual inspection of cracks, raveling, bleeding and rutting. However, visual inspection has serious shortcomings which include limited accuracy, subjective results, time consuming and cost ineffective. Based on visual inspection carried out in 2019, it shows that some of the bridges along A1 highway in the Central district have visible signs of damages. Apart from visual bridge inspections there have been no attempts made by the department to develop bridge monitoring mechanism. Lack of bridge monitoring mechanism may have been caused by limited resources, tools and advanced techniques.

Recent studies have attempted to utilize GPS for bridge deformation monitoring [7] [8]. [7] pointed out that GPS is capable of allowing redundant observations whereby the final precision of points can be determined using powerful least squares rigorous adjustment process. Apart from the advantages of GPS, there are limitations in its application. [9] used GPS to determine horizontal and vertical displacement of a bridge structure. In their study they showed that, GPS apart from measuring horizontal and vertical displacement it is also capable of determining frequency. There are various advantages of using GPS to monitor structural deformation including the determination of 3D displacements and its capability of being used in all weather conditions. In addition, data collected at each station is independent and is used in the adjustment process which can reach up to $10-20 \mathrm{~Hz}$ [10]. The obvious limitation is a lack of acquisition of redundant observation when used in real time kinematic [11] and pointed out that the most serious weakness of GPS is its lower accuracy in the determination of height, multipath error, cycle slips and slow sampling rate with real time Kinematic observation, the quality of the result is compromised by insufficient observations. [12] used GPS, Least Squares Solution and Kalman filter to determine horizontal and vertical displacements of a bridge. The result shows that, the displacements were obtained when the vehicle passes along the surface of the bridge and that the result obtained from 
Kalman filter and Least Squares Solution were almost the same. [13] used GPS and a higher rate carrier receiver to monitor bridge deformation in a short baseline. The result shows that high rate receivers performed well which indicates that selection of best receiver can significantly improve the results. [14] used GPS, Wavelet Principal Component (WPC) analysis and Fast Fourier Transformation (FFT) to determine deformation effects of Monsoura Bridge in Egypt. The result shows that the Wavelet was effective in eliminating GPS noise encountered during GPS campaign. [15] used GPS in RTK mode and integrated with accelerometer sensor to determine dynamic displacement of Nottingham Bridge. In this study it was revealed that some errors from GPS and accelerometer were minimized by using double-differencing and the remaining errors were eliminated by multimode data acquisition technique from GPS. As stated above, however, general achievable accuracies with GPS in horizontal component are in the order of $1 \mathrm{~cm}$. The accuracy is slightly bad in the height component which is mainly due to inherent geometric weakness and atmospheric errors which tend to increase when parts of the space is obstructed by other features and structures [16] [17]. In this work, we used GPS and LVDT for deformation monitoring of a bridge. Our objectives are to 1) determine dynamic displacement of Lotsane Bridge; 2) process and adjust the observations; 3 ) analyze the results and determine the dynamic behavior of the bridge; and 4) determine the displacements in the reference and monitoring points.

\section{Materials and Methods}

\subsection{Study Area}

Lotsane Bridge along Botswana A1 highway was selected as a case study for deformation monitoring. Lotsane Bridge is situated in Palapye $260 \mathrm{~km}$ north from Gaborone city, $168 \mathrm{~km}$ south of Francis town and $28 \mathrm{~km}$ from Serowe village. The bridge was constructed across Lotsane River and it is a link between Gaborone Capital city and neighboring city of Bulawayo in Zimbabwe. The bridge has $37.7 \mathrm{~m}$ long, $12 \mathrm{~m}$ wide and $9.6 \mathrm{~m}$ high. The bridge has two lanes in two way directions and was constructed using reinforcement concrete in three spans and supported with 3 pillars. Figure 1 shows the design of Lotsane Bridge.

\subsection{Planning and Establishment of Reference and Monitoring Points}

The establishment of 8 reference and 14 monitoring points was done in 2019 which were located away and on the surface of the bridge respectively (Mayunga, S.D., and Thabo, 2019). The reference points were established and fixed on a stable ground while the monitoring points were fixed on the bridge with at equal intervals of $6 \mathrm{~m}$ at each sides of the bridge. Two baselines were used and their coordinates were determined using Sokkia GPS equipment. The GPS base was first set over BM5 control point and the rover measured both 
reference and monitoring points for 20 minutes. The same process was repeated using a known point PMR33 to measure both reference and monitoring points. Figure 2 shows BM5 and PM33 and the configuration of reference and monitoring points.

\subsection{Measuring the Stress of the Bridge}

Three LVDT sensors were placed midway of the bridge where the maximum deflection was likely to occur and had room to displace up and down without any constraint. To minimize the observation errors, the LVDTs locations were in constant contact with the steel members of the bridge. One data set consisted of three linear displacement readings were measured in millimeters $(\mathrm{mm})$ and an acceleration data were measured in $(\mathrm{g})$. The observations were repeated throughout the day to obtain sufficient amount of data and saved as a time-series graph and numerical data.
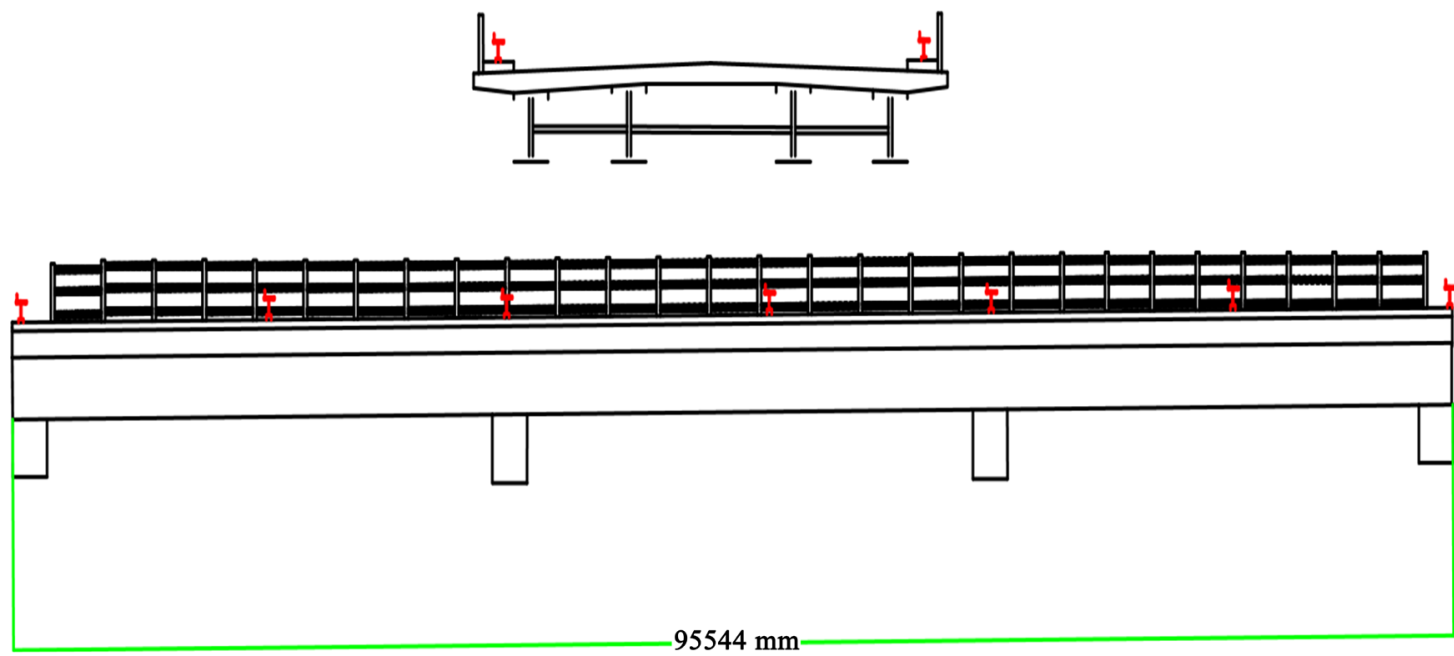

Figure 1. Design of Lotsane bridge, Palapye, Botswana.

\section{Side View}

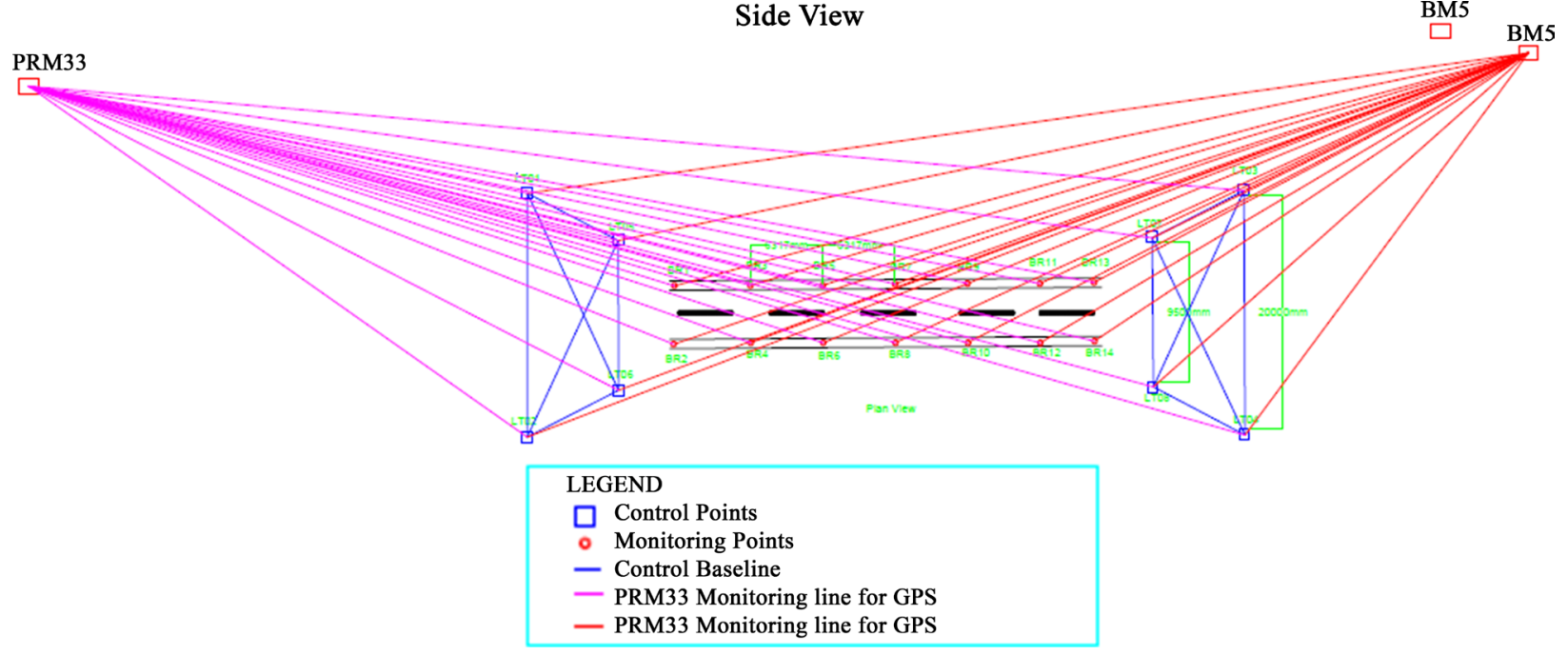

Figure 2. Observation of reference and monitoring points. 


\subsection{GPS Data Processing}

After GPS observations of reference and monitoring points at first epoch, raw data were stored into the internal memory of the receiver and downloaded into the computer derived and adjusted by least squares adjustment using Magnet processing software to determine the reliability of the adjusted coordinates. The GPS reference and monitoring points were adjusted using Least Squares Solution using the following mathematical relationship:

Let line $i j$ be from point $(i)$ to $(j)$ the observation equation is written as:

$$
\begin{gathered}
X_{j}=X_{i}+\Delta X_{i j}+v x_{i j} \\
Y_{j}=Y_{i}+\Delta Y_{i j}+v y_{i j} \\
Z_{j}=Z_{i}+\Delta Z_{i j}+v Z_{i j}
\end{gathered}
$$

Equations (1)-(3) can be compressed in matrix format as:

$$
\begin{gathered}
\left(\begin{array}{c}
x_{1} \\
x_{2} \\
x_{3} \\
\vdots \\
x_{n}
\end{array}\right)=\left(\begin{array}{c}
l_{1} \\
l_{2} \\
l_{3} \\
\vdots \\
l_{n}
\end{array}\right)+\left(\begin{array}{c}
v_{1} \\
v_{2} \\
v_{3} \\
\vdots \\
v_{n}
\end{array}\right) \\
A X=L+V
\end{gathered}
$$

where:

$A$ is the design matrix;

$X$ is the vector of unknowns;

$L$ is the vector of observations and;

$V$ is the vector of residuals.

By inserting a weight $(w)$ and a priori variance $\sigma_{o}^{2}$ for the observations in Equation (4), the cofactor matrix can be given as:

$$
Q_{L}=\frac{1}{\sigma_{o}^{2}} \operatorname{Sum}_{L}
$$

Therefore,

$$
W=Q_{L}^{-1}
$$

The solution becomes well defined by Least Squares principle of $V^{\mathrm{T}} W V=$ minimum. From the above observation equations the least squares principle becomes:

$$
\left(A^{\mathrm{T}} W A\right) X=A^{\mathrm{T}} W L
$$

The vector of unknown can be computed as:

$$
X=\left(A^{\mathrm{T}} W A\right)^{-1}\left(A^{\mathrm{T}} W L\right)
$$

The matrix equation can be computed as:

$$
V=A X-L
$$

The standard deviation of the measurements of unit weight for the weighted 
observations is given as:

$$
\sigma_{0}=\sqrt{\frac{V^{\mathrm{T}} W V}{r}}
$$

where, $r$ is the degree of freedom in the adjustment which is equal to the number of observations minus the number of unknowns.

\subsection{LVDT Data Processing}

The highly precise, universal, and reliable data acquisition system QuantumX was combined with WA-T HBM's sensors and the Catman software to have a complete measurement and testing solution. Catman software was used for data acquisition and analysis of the observations. From the sensor to the software, simply "plug and measure" principle was used to determine the displacement results for each sensor.

\section{Results}

\subsection{Results from GPS Observations}

The final coordinates of reference and monitoring points for zero epoch results were obtained after adjusted using Least Squares principle. Table 1 and Table 2 below show the final coordinates of zero and first epochs which will be used to determine deformation between zero and first epochs. Figure 3, Figure 4 and Figure 5 show the horizontal displacement of some control points like LT5, LT6, LT7 and LT8 which behave as outliers based on their graph trends. The errors on those control points might have been caused by the contractions and expansions characteristics of the soil since there have been some heavy rains between zero and first epochs. Also the discrepancies on the $X$ and $Y$ directions could have been caused erosion of the river soils and vibrations of the bridge due to living loadings. Figure 6 displays the pattern of displacement in the $Z$-axis on which LT4, LT5, LT6 and LT7 were highly affected. These control points are on vicinity where there is movement so it might be assumed that humans or animals tempered with them, hence resulted in their vertical displacements. Figure 7 shows coordinate differences in $x, y$ and $z$ for zero and first epochs while Figure 8 shows the differences of LVDT 1, 3 and 2 respectively. Figures 9-11 shows frequency charts for LVDT 1, 3, and 2 respectively.

\subsection{The Correlation Coefficient}

The correlation coefficient for the observations, denoted by $\rho$, tells how closely data in a scatterplot fall along a straight line. The closer that the absolute value of $\rho$ is close to one, the better that the data are described by a linear equation. If $\hat{\rho}=1$ or $\hat{\rho}=-1$ then the data set is perfectly aligned. Data sets with values of $\rho$ close to zero show little to no straight-line relationship.

$$
\hat{\rho}=\frac{s_{x y}}{s_{x} s_{y}}
$$


Table 1. Final adjusted GPS coordinates obtained from zero epoch (2019).

\begin{tabular}{|c|c|c|c|}
\hline Name & Northing (m) & Easting (m) & Heights (m) \\
\hline LT01 & $2,494,370.393$ & -8565.250 & 919.341 \\
\hline LT02 & $2,494,343.838$ & -8515.565 & 918.928 \\
\hline LT03 & $2,494,332.774$ & -8579.381 & 918.478 \\
\hline LT04 & $2,494,312.603$ & -8553.984 & 918.238 \\
\hline LT05 & $2,494,224.355$ & -8678.514 & 919.688 \\
\hline LT06 & $2,494,188.693$ & -8636.932 & 919.631 \\
\hline LT07 & $2,494,245.301$ & -8658.604 & 918.489 \\
\hline LT08 & $2,494,226.059$ & -8622.229 & 918.748 \\
\hline BR01 & $2,494,285.520$ & -8590.892 & 920.522 \\
\hline BR02 & $2,494,290.460$ & -8597.178 & 920.521 \\
\hline BR03 & $2,494,280.551$ & -8594.739 & 920.562 \\
\hline BR04 & $2,494,285.511$ & -8601.071 & 920.581 \\
\hline BR05 & $2,494,275.613$ & -8598.553 & 920.575 \\
\hline BR06 & $2,494,280.582$ & -8604.914 & 920.586 \\
\hline BR07 & $2,494,270.652$ & -8602.370 & 920.590 \\
\hline BR08 & $2,494,275.593$ & -8608.755 & 920.604 \\
\hline BR09 & $2,494,265.742$ & -8606.255 & 920.590 \\
\hline BR10 & $2,494,270.688$ & -8612.587 & 920.595 \\
\hline BR11 & $2,494,260.811$ & -8610.097 & 920.567 \\
\hline BR12 & $2,494,265.691$ & -8616.379 & 920.570 \\
\hline BR13 & $2,494,255.817$ & -8613.918 & 920.510 \\
\hline BR14 & $2,494,260.823$ & -8620.304 & 920.527 \\
\hline
\end{tabular}

Table 2. Final adjusted GPS coordinates computed from first epoch (2020).

\begin{tabular}{cccc}
\hline Name & Northing $(\mathrm{m})$ & Easting $(\mathrm{m})$ & Heights $(\mathrm{m})$ \\
\hline LT01 & $2,494,370.454$ & -8565.396 & 919.341 \\
LT02 & $2,494,332.824$ & -8515.532 & 918.928 \\
LT03 & $2,494,332.774$ & -8579.746 & 918.478 \\
LT04 & $2,494,312.603$ & -8553.984 & 918.238 \\
LT05 & $2,494,224.355$ & -8678.673 & 919.688 \\
LT06 & $2,494,188.693$ & -8637.081 & 919.631 \\
LT07 & $2,494,245.301$ & -8554.141 & 918.489 \\
LT08 & $2,494,226.059$ & -8515.693 & 918.748 \\
BR01 & $2,494,285.583$ & -8590.892 & 920.522 \\
BR02 & $2,494,290.496$ & -8597.178 & 920.521 \\
BR03 & $2,494,280.609$ & -8594.739 & 920.562
\end{tabular}




\begin{tabular}{rlll} 
Continued & & & \\
\hline BR04 & $2,494,285.553$ & -8601.071 & 920.581 \\
BR05 & $2,494,275.692$ & -8598.553 & 920.575 \\
BR06 & $2,494,280.624$ & -8604.914 & 920.586 \\
BR07 & $2,494,270.734$ & -8602.370 & 920.590 \\
BR08 & $2,494,275.666$ & -8608.755 & 920.604 \\
BR09 & $2,494,265.814$ & -8606.255 & 920.590 \\
BR10 & $2,494,270.758$ & -8612.587 & 920.595 \\
BR11 & $2,494,260.876$ & -8610.097 & 920.567 \\
BR12 & $2,494,265.748$ & -8616.379 & 920.570 \\
BR13 & $2,494,255.888$ & -8613.918 & 920.510 \\
BR14 & $2,494,260.874$ & -8620.304 & 920.527 \\
\hline
\end{tabular}

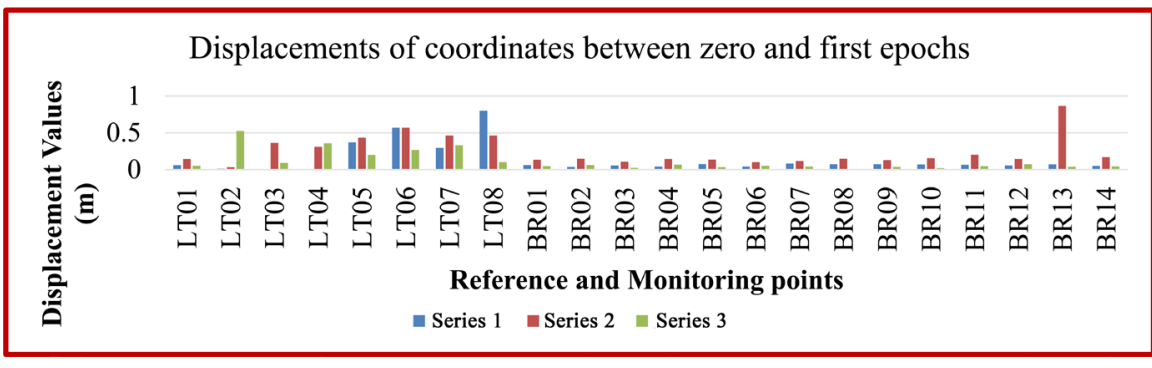

Figure 3. Coordinate difference from zero epoch in $\Delta x, \Delta y$ and $\Delta z$.

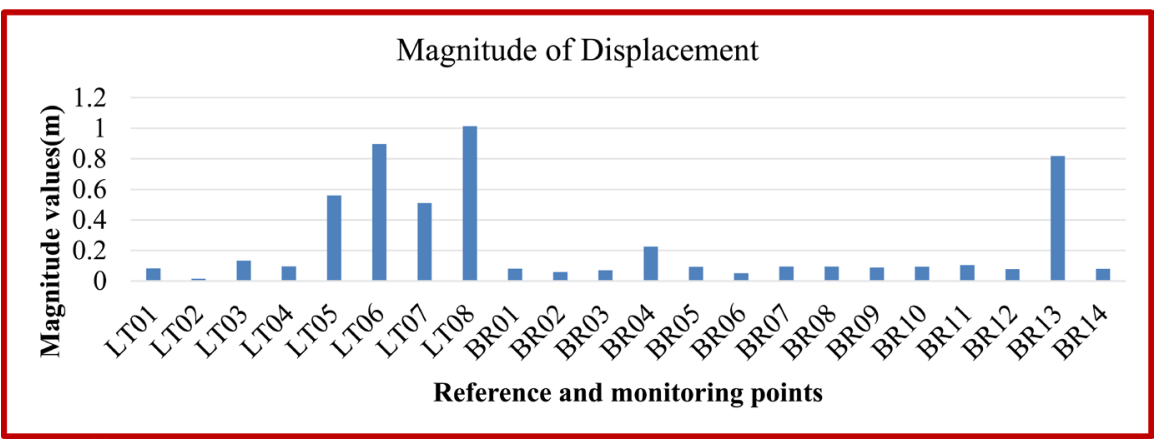

Figure 4. Magnitude of displacement of reference and monitoring points between zero and first epoch.

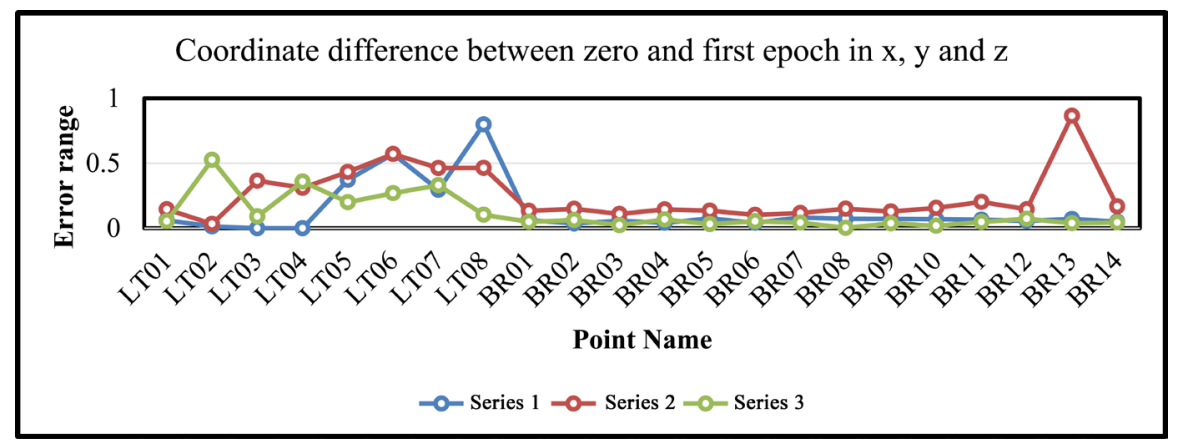

Figure 5. Displacement pattern in $\Delta x, \Delta y$ and $\Delta z$ between zero and first epochs. 


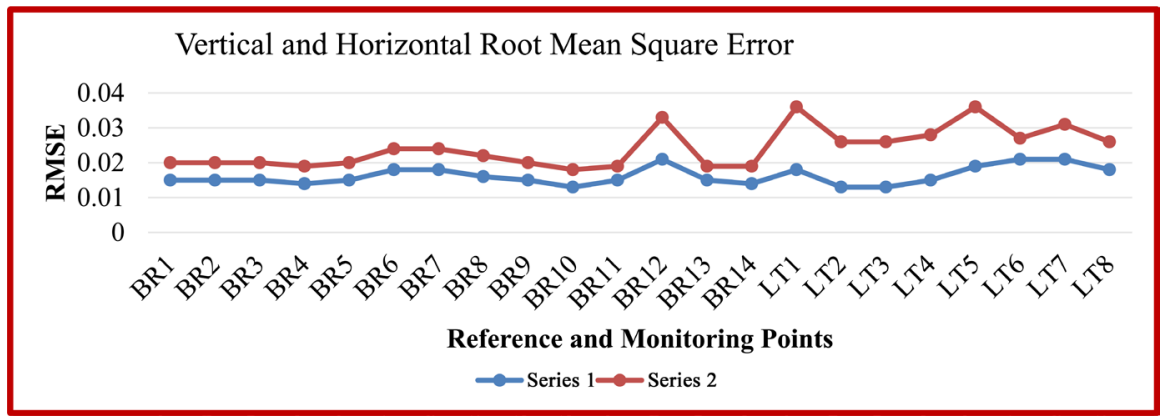

Figure 6. Residuals of reference and monitoring points from GPS observation between zero and first epochs.

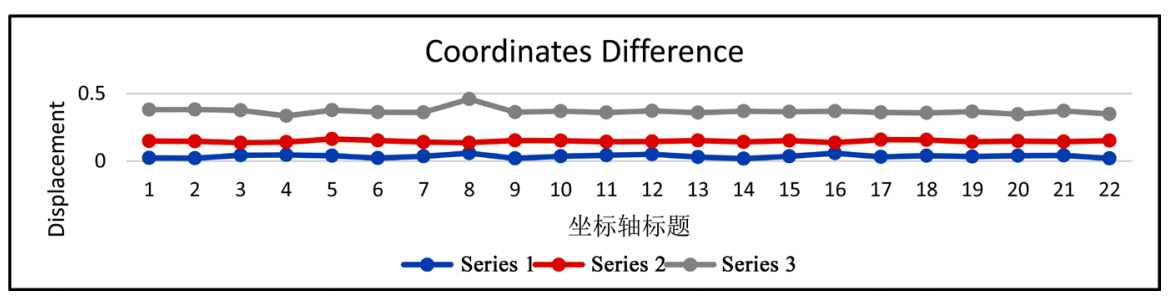

Figure 7. Coordinates differences in $x, y$ and $z$.

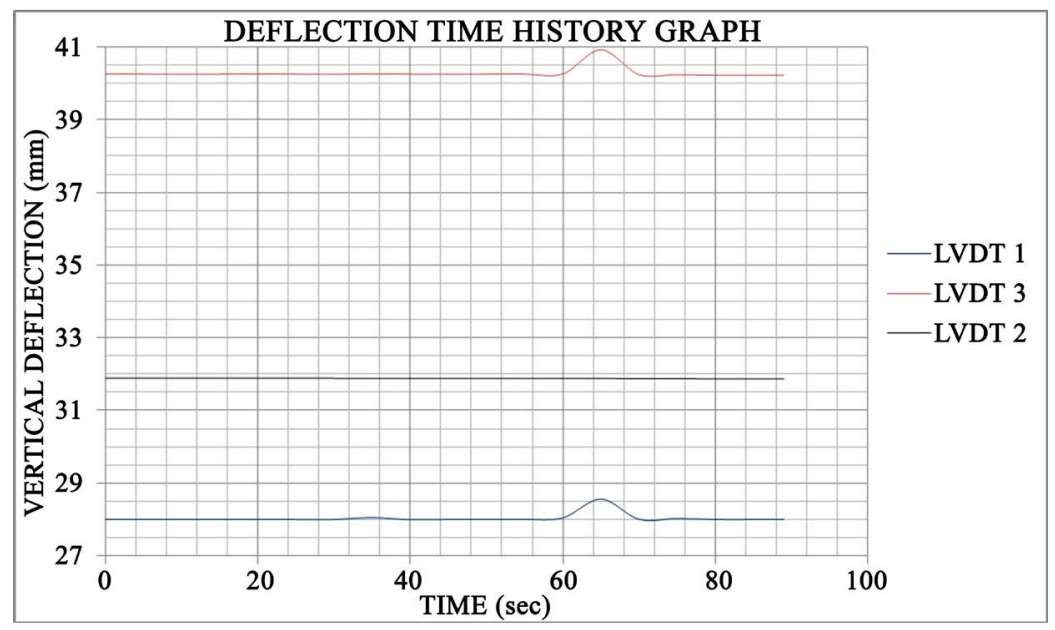

Figure 8. Deflection of LVDT 1, 2 and 3.

where:

$$
\begin{gathered}
\bar{x}=0.016227 \\
\bar{y}=0.024227 \\
s_{x y}=\sum \frac{(x-\bar{x})(y-\bar{y})}{n-1} \\
s_{x y}=\frac{0.000209864}{21}=9.993 \times 10^{-6} \\
s_{x}^{2}=\sum \frac{(x-\bar{x})^{2}}{n-1} \\
s_{x}^{2}=\frac{0.000141864}{21}=6.755 \times 10^{-6}
\end{gathered}
$$




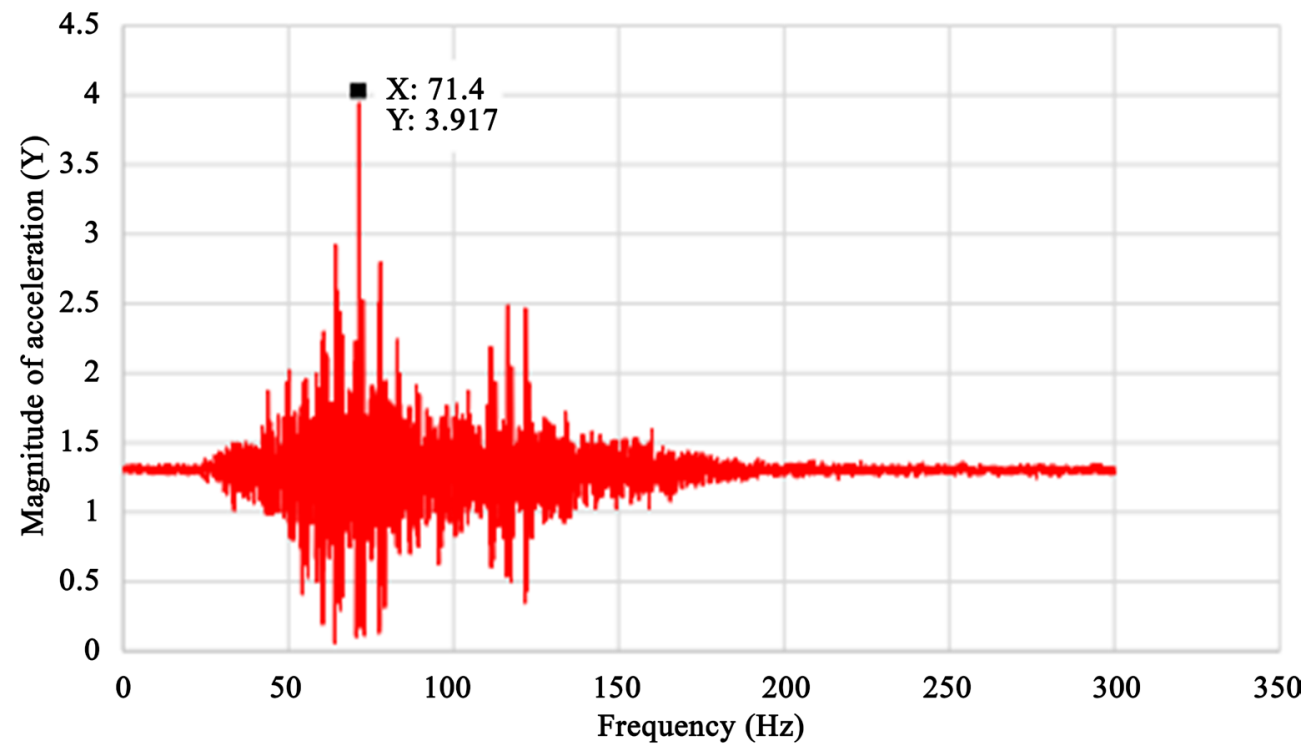

Figure 9. Frequency chart for LVDT 1.

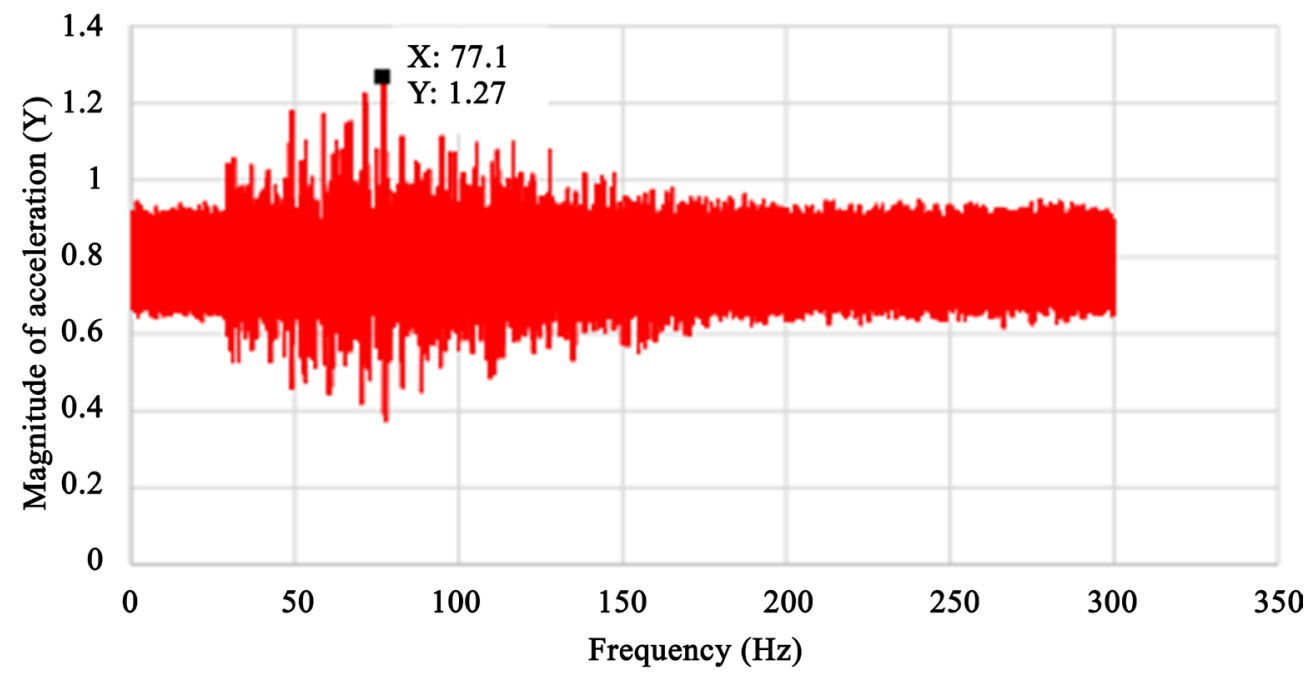

Figure 10. Frequency chart for LVDT 2.

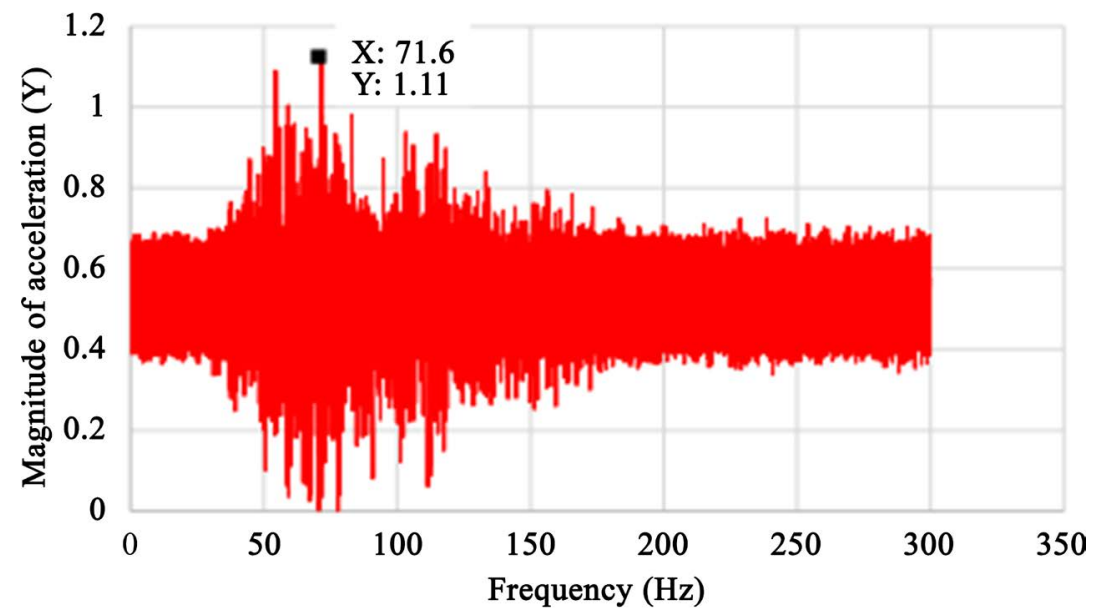

Figure 11. Frequency chart for LVDT 3. 


$$
\begin{gathered}
s_{y}^{2}=\sum \frac{(y-\bar{y})^{2}}{n-1} \\
s_{y}^{2}=\frac{0.000673864}{21}=3.20887 \times 10^{-5} \\
\hat{\rho}=\frac{9.99351 \times 10^{-6}}{0.002599117 \times 0.00566493}=0.679
\end{gathered}
$$

The Standard Deviations

$$
\begin{gathered}
\sigma_{x}=\sqrt{\frac{\sum_{n=1}^{n} v_{x}^{2}}{n-1}} \\
\sigma_{x}=0.0168 \\
\sigma_{y}=\sqrt{\frac{\sum_{n=1}^{n} v_{y}^{2}}{n-1}} \\
\sigma_{y}=0.0254
\end{gathered}
$$

where:

$$
\begin{aligned}
& \sigma_{x}=\text { Standard deviation; } \\
& n=\text { sample; } \\
& V=\text { residuals. }
\end{aligned}
$$

\section{Discussion}

\subsection{GPS Data Analysis}

The GPS observations and adjustment of reference and monitoring points of zero epochs were processed in 2019 while GPS observations and adjustment of reference and monitoring points of first epoch were processed in 2020. The final adjusted GPS coordinates for zero and first epochs were computed and compared to determine whether there are displacements within the epochs. Table 3 shows the comparison of coordinates between zero and first epoch while Table 4 shows the difference in coordinates in $x, y$ and $z$ between epochs. The outliers might have been caused by movements of reference points due to heavy rains experienced in 2020. The maximum residuals between zero and first epoch are $0.021 \mathrm{~m}$ and $0.036 \mathrm{~m}$ in $x$ and $y$ respectively, which all fall on the possible magnitudes for systematic GPS errors. All directions of displacement for reference and monitoring points are in the first quadrant as shown in Table 5. Table 6, Table 7, Tables 10-12 show the residuals of observations in $x$ and $y$, magnitude of displacement, final coordinates of reference and monitoring points, deflection values of LVDT respectively.

\subsection{Results from LVDT Observations}

Table 8 below shows the data obtained using a series of three LVDT's to determine the vertical deflections from traffic loadings on the Lotsane Bridge.

The output signal of the frequency domain is shown by Figures 9-11. From the figures, the peak frequencies formed are an estimate of the natural frequency of the bridge section and it clearly shows the dominant frequency of $77.1 \mathrm{~Hz}$ on LVDT 2. 
Table 3. Comparison of GPS coordinates between zero (2019) and first epoch (2020).

\begin{tabular}{|c|c|c|c|c|c|c|}
\hline Name & $\begin{array}{l}\text { Northing }(\mathrm{m}) \\
\text { Zero Epoch }\end{array}$ & $\begin{array}{l}\text { Easting }(\mathrm{m}) \\
\text { Zero Epoch }\end{array}$ & $\begin{array}{l}\text { Heights }(\mathrm{m}) \\
\text { Zero Epoch }\end{array}$ & $\begin{array}{l}\text { Northing (m) } \\
\text { First Epoch }\end{array}$ & $\begin{array}{l}\text { Easting (m) } \\
\text { First Epoch }\end{array}$ & $\begin{array}{l}\text { Heights }(\mathrm{m}) \\
\text { First Epoch }\end{array}$ \\
\hline LT01 & $2,494,370.393$ & -8565.250 & 919.341 & $2,494,370.454$ & -8565.396 & 919.288 \\
\hline LT02 & $2,494,343.838$ & -8515.565 & 918.928 & $2,494,343.824$ & 8515.532 & 918.402 \\
\hline LT03 & $2,494,332.774$ & -8579.381 & 918.478 & $2,494,332.774$ & -8579.746 & 918.387 \\
\hline LT04 & $2,494,312.603$ & -8553.984 & 918.238 & $2,494,312.603$ & -8678.673 & 918.597 \\
\hline LT05 & $2,494,224.355$ & -8678.514 & 919.688 & $2,494,224.727$ & -8678.081 & 919.488 \\
\hline LT06 & $2,494,188.693$ & -8636.932 & 919.631 & $2,494,188.122$ & -8636.361 & 919.361 \\
\hline LT07 & $2,494,245.301$ & -8658.604 & 918.489 & $2,494,245.597$ & -8658.141 & 918.158 \\
\hline LT08 & $2,494,226.059$ & -8622.229 & 918.748 & $2,494,226.857$ & -8622.693 & 918.852 \\
\hline BR01 & $2,494,285.520$ & -8590.892 & 920.522 & $2,494,285.583$ & -8590.026 & 920.473 \\
\hline BR02 & $2,494,290.460$ & -8597.178 & 920.521 & $2,494,290.496$ & -8597.327 & 920.458 \\
\hline BR03 & $2,494,280.551$ & -8594.739 & 920.562 & $2,494,280.609$ & -8594.849 & 920.538 \\
\hline BR04 & $2,494,285.511$ & -8601.071 & 920.581 & $2,494,285.553$ & -8601.216 & 920.514 \\
\hline BR05 & $2,494,275.613$ & -8598.553 & 920.575 & $2,494,275.692$ & -8598.688 & 920.543 \\
\hline BR06 & $2,494,280.582$ & -8604.914 & 920.586 & $2,494,280.624$ & -8605.017 & 920.532 \\
\hline BR07 & $2,494,270.652$ & -8602.370 & 920.590 & $2,494,270.734$ & -8602.487 & 920.548 \\
\hline BR08 & $2,494,275.593$ & -8608.755 & 920.604 & $2,494,275.666$ & -8608.905 & 920.574 \\
\hline BR09 & $2,494,265.742$ & -8606.255 & 920.590 & $2,494,265.814$ & -8606.384 & 920.553 \\
\hline BR10 & $2,494,270.688$ & -8612.587 & 920.595 & $2,494,270.758$ & -8612.743 & 920.576 \\
\hline BR11 & $2,494,260.811$ & -8610.097 & 920.567 & $2,494,260.876$ & -8610.299 & 920.519 \\
\hline BR12 & $2,494,265.691$ & -8616.379 & 920.570 & $2,494,265.748$ & -8616.525 & 920.497 \\
\hline BR13 & $2,494,255.817$ & -8613.918 & 920.510 & $2,494,255.888$ & -8614.053 & 920.471 \\
\hline BR14 & $2,494,260.823$ & -8620.304 & 920.527 & $2,494,260.874$ & -8620.472 & 920.483 \\
\hline
\end{tabular}

Table 4. Adjusted GPS coordinates between zero (2019) and first epochs (2020) in $\Delta N$, $\Delta E$, and $\Delta H$.

\begin{tabular}{cccc}
\hline Name & $\begin{array}{c}\Delta \boldsymbol{N}(\mathrm{m}) \\
\text { Zero Epoch to First Epoch }\end{array}$ & $\begin{array}{c}\Delta \boldsymbol{E}(\mathrm{m}) \\
\text { Zero Epoch to First Epoch }\end{array}$ & $\begin{array}{c}\Delta H(\mathrm{~m}) \\
\text { Zero Epoch to First Epoch }\end{array}$ \\
\hline LT01 & 0.061 & 0.146 & 0.053 \\
LT02 & 0.014 & 0.033 & 0.526 \\
LT03 & 0.000 & 0.365 & 0.091 \\
LT04 & 0.000 & 0.311 & 0.359 \\
LT05 & 0.372 & 0.433 & 0.200 \\
LT06 & 0.571 & 0.571 & 0.270 \\
LT07 & 0.296 & 0.463 & 0.331 \\
LT08 & 0.798 & 0.464 & 0.104 \\
BR01 & 0.063 & 0.134 & 0.049 \\
BR02 & 0.036 & 0.149 & 0.063 \\
BR03 & 0.058 & 0.110 & 0.024 \\
BR04 & 0.042 & 0.145 & 0.067 \\
\hline
\end{tabular}




\section{Continued}

\begin{tabular}{llll}
\hline BR05 & 0.075 & 0.135 & 0.032 \\
BR06 & 0.042 & 0.103 & 0.054 \\
BR07 & 0.082 & 0.117 & 0.042 \\
BR08 & 0.073 & 0.150 & 0.003 \\
BR09 & 0.072 & 0.129 & 0.037 \\
BR10 & 0.070 & 0.156 & 0.019 \\
BR11 & 0.065 & 0.202 & 0.048 \\
BR12 & 0.057 & 0.146 & 0.073 \\
BR13 & 0.071 & 0.865 & 0.039 \\
BR14 & 0.051 & 0.168 & 0.044 \\
\hline
\end{tabular}

Table 5. Shows the horizontal and vertical magnitude displacement and direction of displacements.

\begin{tabular}{|c|c|c|c|c|c|}
\hline Name & $\begin{array}{c}\Delta E(\mathrm{~m}) \text { Zero } \\
\text { Epoch to First } \\
\text { Epoch }\end{array}$ & $\begin{array}{c}\Delta N(\mathrm{~m}) \text { Zero } \\
\text { Epoch to First } \\
\text { Epoch }\end{array}$ & $\begin{array}{c}\Delta Z(\mathrm{~m}) \text { Zero } \\
\text { Epoch to First } \\
\text { Epoch }\end{array}$ & $\begin{array}{c}\text { Magnitude of } \\
\text { displacement } \\
D_{n}(\mathrm{~m})\end{array}$ & $\begin{array}{c}\text { Direction of } \\
\text { displacement } \\
\theta\end{array}$ \\
\hline LT01 & 0.061 & 0.146 & 0.053 & 0.082 & $67^{\circ} 19^{\prime} 28^{\prime \prime}$ \\
\hline LT02 & 0.014 & 0.033 & 0.526 & 0.015 & $67^{\circ} 00^{\prime} 40^{\prime \prime}$ \\
\hline LT03 & 0.000 & 0.365 & 0.091 & 0.133 & $00^{\circ} 00^{\prime} 00^{\prime \prime}$ \\
\hline LT04 & 0.000 & 0.311 & 0.359 & 0.096 & $00^{\circ} 00^{\prime} 00^{\prime \prime}$ \\
\hline LT05 & 0.372 & 0.433 & 0.200 & 0.559 & $49^{\circ} 20^{\prime} 00^{\prime \prime}$ \\
\hline LT06 & 0.571 & 0.571 & 0.270 & 0.897 & $45^{\circ} 00^{\prime} 00^{\prime \prime}$ \\
\hline LT07 & 0.296 & 0.463 & 0.331 & 0.510 & $57^{\circ} 24^{\prime} 32^{\prime \prime}$ \\
\hline LT08 & 0.798 & 0.464 & 0.104 & 1.013 & $30^{\circ} 10^{\prime} 34^{\prime \prime}$ \\
\hline BR01 & 0.063 & 0.134 & 0.049 & 0.080 & $64^{\circ} 49^{\prime} 10^{\prime \prime}$ \\
\hline BR02 & 0.036 & 0.149 & 0.063 & 0.058 & $76^{\circ} 25^{\prime} 01^{\prime \prime}$ \\
\hline BR03 & 0.058 & 0.110 & 0.024 & 0.070 & $62^{\circ} 11^{\prime} 54^{\prime \prime}$ \\
\hline BR04 & 0.042 & 0.145 & 0.067 & 0.225 & $73^{\circ} 50^{\prime} 45^{\prime \prime}$ \\
\hline BR05 & 0.075 & 0.135 & 0.032 & 0.093 & $60^{\circ} 56^{\prime} 43^{\prime \prime}$ \\
\hline BR06 & 0.042 & 0.103 & 0.054 & 0.052 & $67^{\circ} 48^{\prime} 57^{\prime \prime}$ \\
\hline BR07 & 0.082 & 0.117 & 0.042 & 0.095 & $54^{\circ} 58^{\prime} 30^{\prime \prime}$ \\
\hline BR08 & 0.073 & 0.150 & 0.003 & 0.095 & $64^{\circ} 02^{\prime} 57^{\prime \prime}$ \\
\hline BR09 & 0.072 & 0.129 & 0.037 & 0.088 & $60^{\circ} 49^{\prime} 56^{\prime \prime}$ \\
\hline BR10 & 0.070 & 0.156 & 0.019 & 0.094 & $65^{\circ} 50^{\prime} 00^{\prime \prime}$ \\
\hline BR11 & 0.065 & 0.202 & 0.048 & 0.105 & $72^{\circ} 09^{\prime} 45^{\prime \prime}$ \\
\hline BR12 & 0.057 & 0.146 & 0.073 & 0.078 & $68^{\circ} 40^{\prime} 25^{\prime \prime}$ \\
\hline BR13 & 0.071 & 0.865 & 0.039 & 0.819 & $85^{\circ} 18^{\prime} 27^{\prime \prime}$ \\
\hline BR14 & 0.051 & 0.168 & 0.044 & 0.079 & $73^{\circ} 06^{\prime} 47^{\prime \prime}$ \\
\hline
\end{tabular}


Table 6. Residuals of reference and monitoring points from GPS observation.

\begin{tabular}{|c|c|c|}
\hline Point No. & Residual in $\mathbf{x}$ & Residual in y \\
\hline BR1 & 0.015 & 0.020 \\
\hline BR2 & 0.015 & 0.020 \\
\hline BR3 & 0.015 & 0.020 \\
\hline BR4 & 0.014 & 0.019 \\
\hline BR5 & 0.015 & 0.020 \\
\hline BR6 & 0.018 & 0.024 \\
\hline BR7 & 0.018 & 0.024 \\
\hline BR8 & 0.016 & 0.022 \\
\hline BR9 & 0.015 & 0.020 \\
\hline BR10 & 0.013 & 0.018 \\
\hline BR11 & 0.015 & 0.019 \\
\hline BR12 & 0.021 & 0.033 \\
\hline BR13 & 0.015 & 0.019 \\
\hline BR14 & 0.014 & 0.019 \\
\hline LT1 & 0.018 & 0.036 \\
\hline LT2 & 0.013 & 0.026 \\
\hline LT3 & 0.013 & 0.026 \\
\hline LT4 & 0.015 & 0.028 \\
\hline LT5 & 0.019 & 0.036 \\
\hline LT6 & 0.021 & 0.027 \\
\hline LT7 & 0.021 & 0.031 \\
\hline LT8 & 0.018 & 0.026 \\
\hline
\end{tabular}

Table 7. Magnitude of displacement in $x, y$ and $z$.

\begin{tabular}{cccccc}
\hline Name & $d \boldsymbol{N}(\mathrm{m})$ & $d E(\mathrm{~m})$ & $\boldsymbol{d H t}(\mathrm{m})$ & Horz RMS & Vert RMS \\
\hline PRM33-PRM30 & -367.537 & -158.898 & 1.108 & 0.002 & 0.003 \\
PRM33-LT-01 & 1110.753 & 565.95 & -4.814 & 0.002 & 0.003 \\
PRM33-LT-02 & 1084.198 & 615.635 & -5.225 & 0.002 & 0.003 \\
PRM33-LT-03 & 1073.134 & 551.819 & -5.675 & 0.002 & 0.003 \\
PRM33-LT-04 & 1052.963 & 577.216 & -5.91 & 0.002 & 0.003 \\
PRM33-LT-05 & 964.715 & 452.686 & -4.482 & 0.002 & 0.003 \\
PRM33-LT-06 & 929.053 & 494.268 & -4.627 & 0.002 & 0.003 \\
PRM33-LT-07 & 985.661 & 472.596 & -5.67 & 0.002 & 0.003 \\
PRM33-LT-08 & 966.419 & 508.971 & -5.688 & 0.002 & 0.003 \\
PRM33-BR-01 & 1025.88 & 540.308 & -3.637 & 0.002 & 0.003 \\
PRM33-BR-02 & 1030.82 & 534.022 & -3.628 & 0.002 & 0.003 \\
\hline
\end{tabular}




\begin{tabular}{llllll} 
Continued & \multicolumn{7}{l}{} \\
\hline PRM33-BR-03 & 1020.911 & 536.461 & -3.592 & 0.002 & 0.003 \\
PRM33-BR-04 & 1025.871 & 530.129 & -3.582 & 0.002 & 0.003 \\
PRM33-BR-05 & 1015.973 & 532.647 & -3.576 & 0.002 & 0.004 \\
PRM33-BR-06 & 1020.942 & 526.286 & -3.559 & 0.002 & 0.003 \\
PRM33-BR-07 & 1011.012 & 528.83 & -3.573 & 0.002 & 0.003 \\
PRM33-BR-08 & 1015.953 & 522.445 & -3.538 & 0.002 & 0.003 \\
PRM33-BR-09 & 1006.102 & 524.945 & -3.573 & 0.002 & 0.003 \\
PRM33-BR-10 & 1011.048 & 518.613 & -3.554 & 0.002 & 0.003 \\
PRM33-BR-11 & 1001.171 & 521.103 & -3.601 & 0.002 & 0.003 \\
PRM33-BR-12 & 1006.051 & 514.821 & -3.577 & 0.002 & 0.003 \\
PRM33-BR-13 & 996.177 & 517.282 & -3.651 & 0.002 & 0.003 \\
PRM33-BR-14 & 1001.183 & 510.896 & -3.623 & 0.002 & 0.003 \\
\hline
\end{tabular}

Table 8. Comparison of GPS height and precise leveling.

\begin{tabular}{|c|c|c|c|c|c|c|c|c|c|}
\hline \multirow[b]{3}{*}{ Name } & \multicolumn{3}{|c|}{ Reference point $=$ PRM33 } & \multicolumn{3}{|c|}{ Reference Point $=$ BM5 } & \multirow{2}{*}{\multicolumn{3}{|c|}{ Coordinate Differences }} \\
\hline & $2,493,259.640$ & -9131.200 & 930.26 & $2,499,267.47$ & $-13,034.15$ & 982.77 & & & \\
\hline & Northing (m) & Easting $(\mathrm{m})$ & $H$ & Northing (m) & Easting $(\mathrm{m})$ & $H t$ & $\begin{array}{l}\Delta \text { Northings } \\
\text { (m) }\end{array}$ & $\begin{array}{l}\Delta \text { Eastings } \\
\text { (m) }\end{array}$ & $\begin{array}{l}\Delta H \\
(\mathrm{~m})\end{array}$ \\
\hline LT01 & $2,494,370.393$ & -8565.25 & 925.255 & $2,494,370.416$ & -8565.398 & 925.635 & 0.023 & 0.148 & 0.380 \\
\hline LT02 & $2,494,343.838$ & -8515.565 & 924.843 & $2,494,343.859$ & -8515.711 & 925.224 & 0.021 & 0.146 & 0.381 \\
\hline LT03 & $2,494,332.774$ & -8579.381 & 924.394 & $2,494,332.817$ & -8579.517 & 924.77 & 0.043 & 0.136 & 0.376 \\
\hline LT04 & $2,494,312.603$ & -8553.984 & 924.158 & $2,494,312.558$ & -8554.124 & 924.492 & 0.045 & 0.140 & 0.334 \\
\hline LT05 & $2,494,224.355$ & -8678.514 & 925.587 & $2,494,224.395$ & -8678.677 & 925.964 & 0.04 & 0.163 & 0.377 \\
\hline LT06 & $2,494,188.693$ & -8636.932 & 925.442 & $2,494,188.715$ & -8637.084 & 925.804 & 0.022 & 0.152 & 0.362 \\
\hline LT07 & $2,494,245.301$ & -8658.604 & 924.399 & $2,494,245.336$ & -8658.744 & 924.759 & 0.035 & 0.140 & 0.360 \\
\hline LT08 & $2,494,226.059$ & -8622.229 & 924.38 & $2,494,226.117$ & -8622.365 & 924.839 & 0.058 & 0.136 & 0.459 \\
\hline BR01 & $2,494,285.520$ & -8590.892 & 926.432 & $2,494,285.540$ & -8591.044 & 926.794 & 0.02 & 0.152 & 0.362 \\
\hline BR02 & $2,494,290.460$ & -8597.178 & 926.441 & $2,494,290.495$ & -8597.329 & 926.81 & 0.035 & 0.151 & 0.369 \\
\hline BR03 & $2,494,280.551$ & -8594.739 & 926.477 & $2,494,280.594$ & -8594.882 & 926.836 & 0.043 & 0.143 & 0.359 \\
\hline BR04 & $2,494,285.511$ & -8601.071 & 926.487 & $2,494,285.561$ & -8601.216 & 926.859 & 0.05 & 0.145 & 0.372 \\
\hline BR05 & $2,494,275.613$ & -8598.553 & 926.493 & $2,494,275.643$ & -8598.705 & 926.851 & 0.03 & 0.152 & 0.358 \\
\hline BR06 & $2,494,280.582$ & -8604.914 & 926.51 & $2,494,280.600$ & -8605.055 & 926.879 & 0.018 & 0.141 & 0.369 \\
\hline BR07 & $2,494,270.652$ & -8602.37 & 926.495 & $2,494,270.687$ & -8602.521 & 926.86 & 0.035 & 0.151 & 0.365 \\
\hline BR08 & $2,494,275.593$ & -8608.755 & 926.531 & $2,494,275.651$ & -8608.891 & 926.9 & 0.058 & 0.136 & 0.369 \\
\hline BR09 & $2,494,265.742$ & -8606.255 & 926.496 & $2,494,265.773$ & -8606.413 & 926.857 & 0.031 & 0.158 & 0.361 \\
\hline BR10 & $2,494,270.688$ & -8612.587 & 926.515 & $2,494,270.728$ & -8612.744 & 926.871 & 0.04 & 0.157 & 0.356 \\
\hline BR11 & $2,494,260.811$ & -8610.097 & 926.468 & $2,494,260.844$ & -8610.24 & 926.834 & 0.033 & 0.143 & 0.366 \\
\hline BR12 & $2,494,265.691$ & -8616.379 & 926.492 & $2,494,265.731$ & -8616.527 & 926.838 & 0.04 & 0.148 & 0.346 \\
\hline BR13 & $2,494,255.817$ & -8613.918 & 926.418 & $2,494,255.859$ & -8614.062 & 926.79 & 0.042 & 0.144 & 0.372 \\
\hline BR14 & $2,494,260.823$ & -8620.304 & 926.446 & $2,494,260.843$ & -8620.455 & 926.795 & 0.02 & 0.151 & 0.349 \\
\hline
\end{tabular}


Table 9. Comparison of GPS height and precise leveling.

\begin{tabular}{lccc}
\hline Point & GPS height $(\mathrm{m})$ & Precise Levelling $(\mathrm{m})$ & Difference $\left(\Delta H_{\mathrm{GPS}}-\Delta H_{\mathrm{LEVEL}}\right)(\mathrm{m})$ \\
\hline LT01 & 925.255 & 919.341 & 5.914 \\
LT02 & 924.843 & 918.928 & 5.915 \\
LT03 & 924.394 & 918.478 & 5.916 \\
LT04 & 924.158 & 918.238 & 5.920 \\
LT05 & 925.587 & 919.688 & 5.899 \\
LT06 & 925.442 & 919.631 & 5.811 \\
LT08 & 924.399 & 918.489 & 8.910 \\
BR01 & 924.380 & 918.748 & 5.632 \\
BR02 & 926.432 & 920.522 & 5.910 \\
BR03 & 926.477 & 920.562 & 5.917 \\
BR04 & 926.487 & 920.581 & 9.906 \\
BR05 & 926.493 & 920.575 & 5.924 \\
BR06 & 926.510 & 920.586 & 5.924 \\
BR07 & 926.531 & 920.590 & 5.905 \\
BR08 & 926.531 & 920.590 & 5.927 \\
BR09 & 926.496 & 920.590 & 5.906 \\
BR10 & 926.515 & 920.595 & 5.920 \\
BR11 & 926.468 & 920.567 & 5.901 \\
BR12 & 926.492 & 920.570 & 5.919 \\
BR13 & 926.418 & 920.510 & 908 \\
BR14 & 926.446 & 920.527 & \\
\hline & & & \\
\hline
\end{tabular}

Table 10. Final coordinates of reference and monitoring points.

\begin{tabular}{cccc}
\hline Name & Northing $(\mathrm{m})$ & Easting $(\mathrm{m})$ & Heights $(\mathrm{m})$ \\
\hline LT01 & $2,494,370.393$ & -8565.25 & 919.341 \\
LT02 & $2,494,343.838$ & -8515.565 & 918.928 \\
LT03 & $2,494,332.774$ & -8579.381 & 918.478 \\
LT04 & $2,494,312.603$ & -8553.984 & 918.238 \\
LT05 & $2,494,224.355$ & -8678.514 & 919.688 \\
LT06 & $2,494,188.693$ & -8636.932 & 919.631 \\
LT07 & $2,494,245.301$ & -8658.604 & 918.489 \\
LT08 & $2,494,226.059$ & -8622.229 & 918.748 \\
BR01 & $2,494,285.520$ & -8590.892 & 920.522 \\
BR02 & $2,494,290.460$ & -8597.178 & 920.521 \\
BR03 & $2,494,280.551$ & -8594.739 & 920.562 \\
BR04 & $2,494,285.511$ & -8601.071 & 920.581 \\
& & & \\
\hline & 2 & &
\end{tabular}




\section{Continued}

\begin{tabular}{llll}
\hline BR05 & $2,494,275.613$ & -8598.553 & 920.575 \\
BR06 & $2,494,280.582$ & -8604.914 & 920.586 \\
BR07 & $2,494,270.652$ & -8602.370 & 920.590 \\
BR08 & $2,494,275.593$ & -8608.755 & 920.604 \\
BR09 & $2,494,265.742$ & -8606.255 & 920.590 \\
BR10 & $2,494,270.688$ & -8612.587 & 920.595 \\
BR11 & $2,494,260.811$ & -8610.097 & 920.567 \\
BR12 & $2,494,265.691$ & -8616.379 & 920.570 \\
BR13 & $2,494,255.817$ & -8613.918 & 920.510 \\
BR14 & $2,494,260.823$ & -8620.304 & 920.527 \\
\hline
\end{tabular}

Table 11. Field deflection-time data for LVDT.

\begin{tabular}{|c|c|c|c|}
\hline \multirow{2}{*}{ TIME (sec) } & \multicolumn{3}{|c|}{ VERTICAL DEFLECTION (mm) } \\
\hline & LVDT 1 & LVDT 3 & LVDT 2 \\
\hline 0 & 28.00647 & 40.25415 & 31.89259 \\
\hline 5 & 28.00443 & 40.25446 & 31.89188 \\
\hline 10 & 28.00263 & 40.25342 & 31.89075 \\
\hline 15 & 28.00351 & 40.25442 & 31.88909 \\
\hline 20 & 28.0007 & 40.25384 & 31.88822 \\
\hline 25 & 27.99938 & 40.25355 & 31.88642 \\
\hline 30 & 28.00009 & 40.25264 & 31.88548 \\
\hline 35 & 28.05152 & 40.25834 & 31.88361 \\
\hline 40 & 27.99379 & 40.25397 & 31.88337 \\
\hline 45 & 28.00124 & 40.25169 & 31.88234 \\
\hline 50 & 28.00156 & 40.25399 & 31.8814 \\
\hline 55 & 28.0027 & 40.25428 & 31.87992 \\
\hline 60 & 28.04368 & 40.25927 & 31.87911 \\
\hline 65 & 28.56282 & 40.92585 & 31.88283 \\
\hline 70 & 28.00369 & 40.24071 & 31.87436 \\
\hline 75 & 28.02768 & 40.2412 & 31.87367 \\
\hline 80 & 28.00042 & 40.22477 & 31.87115 \\
\hline 85 & 27.99855 & 40.22374 & 31.86828 \\
\hline 89 & 27.99936 & 40.22451 & 31.86819 \\
\hline
\end{tabular}

Table 12. Deflection of the bridge from LVDT.

\begin{tabular}{cccc}
\hline Span & Position 1 & Position 2 & Position 3 \\
\hline LVDT & LVDT 1 & LVDT2 & LVDT3 \\
Maximum Deflection $(\mathrm{mm})$ & 28.56282 & 31.88283 & 40.92585 \\
\hline
\end{tabular}




\subsection{Live-Load Deflections}

According to AASHTO Standard Specifications (AASHTO, 1996), the limits live-load deflections is $L / 800$ for ordinary bridges and $L / 1000$ for bridges in urban areas that are subject to pedestrian use. Therefore, for Lotsane Bridge the maximum limit is expressed as shown in Equation (21).

$$
\frac{L}{800}
$$

where $\mathrm{L}$ is the length of the bridge in $\mathrm{m}$.

Therefore the maximum deflection is given as $\frac{37.7 \mathrm{~m}}{800}=47.125 \mathrm{~mm}$.

\subsection{Analysis of LVDT Results}

The deflection produced by moving traffic loads on the surface of the bridge shows that the maximum deflection observed was $40.925 \mathrm{~mm}$. The AASHTO Standard Specification (AASHTO, 1996) limits live-load deflections to $L / 800$ for ordinary bridges and $L / 1000$ for bridges in urban areas that are subject to pedestrian use. These limits are required for steel, pre-stressed and reinforced concrete, and other bridge superstructure types. The computed limit live-load deflection for Lotsane Bridge was $47.125 \mathrm{~mm}$. Therefore the bridge's performance with regards to deflections is within the tolerable limit. Finally, the natural filter frequency of the bridge was found to be $50 \mathrm{~Hz}$ in the vertical direction using Bessel low pass filter characteristics.

\section{Conclusions}

Based on this study, the analysis of results rests on the following conclusions:

1) The proposed integrated deformation monitoring scheme using GPS and RTK can provide valuable deformation data of the bridge structure.

2) It was revealed that the maximum displacements detected between zero and first epochs in $\mathrm{x}, \mathrm{y}$ and $\mathrm{z}$ components are $0.798 \mathrm{~m}$, at point LT08, $0.865 \mathrm{~m}$ at point $\mathrm{BR} 13$, and $0.56 \mathrm{~m}$ at point LT02 respectively. 3 . The traffic loads are the main factor affecting bridge cracks.

4) The maximum displacements for sensors 1, 2 and 3 are $28.563 \mathrm{~mm}, 31.883$ $\mathrm{mm}$ and $40.926 \mathrm{~mm}$ respectively.

5) The computed maximum live-load deflection for Lotsane Bridge was 47.125 $\mathrm{mm}$ against $4.09 \mathrm{~mm}$ obtained by LVDT which indicates that the bridge's performance is within the recommended limit.

6) The correlation coefficient for the observations was 0.679 with standard deviations of 0.0168 and 0.0254 in $\mathrm{x}$ and $\mathrm{y}$ respectively.

\section{Acknowledgements}

This work was supported by Botswana International University of Science and Technology. 


\section{Conflicts of Interest}

The authors declare no conflicts of interest regarding the publication of this paper.

\section{References}

[1] Beshr, A.A. (2004) Accurate Surveying Measurements for Smart Structural Members. M.Sc. Thesis, Public Works Department, Faculty of Engineering, Mansoura University, El-Mansoura.

[2] Beshr, A.A. (2010) Development and Innovation of Technologies for Deformation Monitoring of Engineering Structures Using Highly Accurate Modern Surveying Techniques and Instruments. Ph.D. Thesis, Siberian State Academy of Geodesy, Novosibirsk, Surveying Techniques and Instruments.

[3] Daniele, I., et al. (1999) Long-Term Monitoring of a Concrete Bridge with 100+ Fiber Optic Long-Gage Sensors. Proceedings of SPIE, 3587, 1-7.

[4] Erol, S. (2004) A General Review of the Deformation Monitoring Techniques and a Case Study: Analyzing Deformations Using GPS/Levelling. 1-7.

[5] Phares, B.M., et al. (2001) Reliability and Accuracy of Routine Inspection of Highway Bridges. Journal of the Transportation Research Board, 1749, 81-92. https://doi.org/10.3141/1749-13

[6] Bennetts, et al. (2001) Using Data to Explore Trends in Bridge Performance. Journal of Smart Infrastructure and Construction, 171, 14-28.

https://doi.org/10.1680/jsmic.17.00022

[7] Handayani, et al. (2015) Preliminary Study of Bridge Deformation Monitoring Using GPS and CRP (Case Study: Suramadu Bridge). Procedia Environmental Sciences, 24, 266-276. https://doi.org/10.1016/j.proenv.2015.03.035

[8] Mayunga, S.D. and Thabo, R. (2019) Deformation Monitoring of Lotsane Bridge Using Geodetic Method. International Journal of Scientific Engineering and Research, 7, 21-27.

[9] Amin, N.M., et al. (2017) Condition Rating System of Bridges in Malaysia: A Case Study. Journal of Engineering and Applied Sciences, 12, 787-791.

[10] Aktan, A.E., et al. (2020) Development of a Model Health Monitoring Guide for Major Bridges. Technical Report, Drexel University, Philadelphia.

[11] Meng, X., et al. (2011) Using Multi-Constellation GNSS and EGNOS for Bridge Deformation Monitoring.

https://fig.net/resources/proceedings/2011/2011_lsgi/session_3a/meng_gogoi_dods on_roberts_brown.pdf

[12] Kessler, S.S. (2014) Spearing, Structural Health Monitoring of Composite Materials Using Piezoelectric Sensors. Department of Aeronautics and Astronautics, Massachusetts Institute of Technology, Cambridge.

[13] Amin, Z.M. and Akib, W.A.W. (2003) Experimental Detection of the Penang Bridge Vibration with Real Time Kinematic GPS. International Symposium and Exhibition on Geoinformation, Kuala Lumpur, 13-14 October 2003, 9.

[14] Park, H.S., Sohn, H.G., Kimi, I.S. and Park, J.H. (2008) Application of GPS to Monitoring of Wind Induced Responses of High-Rise Building. The Structural Design of Tall and Special Buildings, 17, 117-132. https://doi.org/10.1002/tal.335

[15] Nehdi (2018) Condition Assessment of Reinforced Concrete Bridges: Current Practice and Research Challenges. Infrastructures, 3, 36. 
https://doi.org/10.3390/infrastructures3030036

[16] Featherstone, W.E., Denith, M.C. and Kirby, J.F. (1998) Strategies for the Accurate Determination of Orthometric Heights from GPS. Survey Review, 34, 278-296. https://doi.org/10.1179/sre.1998.34.267.278

[17] Çelik, R.N., et al. (2001) Monitoring Deformation on Karasu Viaduct Using GPS and Precise Levelling Techniques. Kluwer Academic Publishers, Dordrecht. https://doi.org/10.1007/978-94-010-0696-5_28 